\title{
GEO Transformational Leadership and Corporate Entrepreneurship in China
}

\author{
Yaotian Pan, ${ }^{1}$ Alain Verbeke, ${ }^{2,3,4}$ and Wenlong Yuan $^{5}$ \\ ${ }^{1}$ Chinese Academy of Sciences, China, ${ }^{2}$ University of Calgary, Canada, ${ }^{3}$ University of Reading, UK, \\ ${ }^{4}$ Vrije Universiteit Brussel, Belgium, and ${ }^{5}$ University of Manitoba, Canada
}

\begin{abstract}
A chief executive officer (CEO) acting as the firm's transformational leader is typically viewed as instrumental to corporate entrepreneurship in established firms, but how exactly does a higher level of corporate entrepreneurship come about, given a transformational CEO's actions? We suggest that organizational ambidexterity can function as a core mediating mechanism between transformational CEOs and the observed level of corporate entrepreneurship and that the effectiveness of this mediating process varies as a function of critical contingencies related to characteristics of the top management team (TMT), the environment and the organization's design. Our empirical evidence, based on a sample of 145 Chinese private sector firms, and using three primary sources of data (145 CEOs, 506 TMT members, and 1,981 middle managers), provides support for a moderated mediation process. We find that the mediating pathway from transformational leadership to corporate entrepreneurship through organizational ambidexterity is not significant when boundary conditions are ignored. However, when environmental dynamism, TMT collectivism, and structural differentiation are included as moderators, CEO transformational leadership does affect corporate entrepreneurship via the creation and effective functioning of organizational ambidexterity.
\end{abstract}

KEYWORDS ambidexterity, collectivism, corporate entrepreneurship, structural differentiation, transformational leadership

AGGEPTED BY Senior Editor Wu Liu

\section{INTRODUGTION}

The linkages between leadership and corporate entrepreneurship (CE hereafter) have attracted much attention in both public discourse (e.g., Dyer \& Gregersen, 2013) and academic studies (e.g., Dess, Ireland, Zahra, Floyd, Janney, \& Lane, 2003). Corporate entrepreneurship refers to 'the pursuit of entrepreneurial actions and initiatives that transform the established organization through strategic renewal processes and/or extend the firm's scope of operations into new domains, that is, new product-market segments or technological arenas' (Goodale, Kuratko,

Corresponding author: Alain Verbeke (averbeke@ucalgary.ca)

(C) The Author(s), 2021. Published by Cambridge University Press on behalf of The International Association for Chinese Management Research. This is an Open Access article, distributed under the terms of the Creative

Commons Attribution licence (http://creativecommons.org/licenses/by/4.0/), which permits unrestricted re-use, 
Hornsby, \& Covin, 2011: 116). As corporate entrepreneurship activities are critical to create new businesses and build competitive advantage (Zahra, 1996), scholars have paid significant attention to promoting opportunity recognition and exploitation in established firms (e.g., Hornsby, Kuratko, \& Zahra, 2002). Given the significant influence of executives on firm-level strategies, the concept of leadership, especially transformational leadership (TFL), has been highlighted as a major source of CE (e.g., Gumusluoglu \& Ilsev, 2009; Ling, Simsek, Lubatkin, \& Veiga, 2008). Effective transformational leaders supposedly articulate a shared vision of their firm's future and motivate organizational members to respond to the changing environment (Podsakoff, MacKenzie, Moorman, \& Fetter, 1990). More indirectly (but perhaps more importantly, in large firms), they can also promote an entrepreneurial context that will facilitate creative efforts in the organization.

As TFL can fashion the kind of organizational context needed to nurture creative efforts and empower employees to seek innovative approaches, various dimensions of this context, such as organizational climate and culture, have been proposed as a major pathway between TFL and CE, though there has been little empirical exploration of the matter. Jung, Chow, and Wu (2003) did conduct an empirical analysis of the pathway from TFL, going through organizational climate, to affect CE. But this study was based on a sample of only $32 \mathrm{com}-$ panies, and therefore invited more large-scale analyses to be performed. The absence of larger-scale empirical work on TFL-CE linkages led Ling et al. (2008: 570) to call for more research on this subject matter, where the focus, according to these authors, could be on the role of organizational culture.

Besides the paucity of empirical research, past conceptualizations of the organizational context as it could affect the TFL-CE linkage, have focused on specific variables, such as empowering employees, supporting their innovation activities (Jung et al., 2003), and promoting risk-taking behaviors (Ling et al., 2008), while missing the critical challenge of how to mesh the co-existence of emerging businesses (and managerial practices) and established ones. Actually achieving $\mathrm{CE}$ often demands the reconciliation of seemingly contradictory tensions, i.e., the blend of old and new organizational characteristics (Garvin \& Levesque, 2006) and the mixture of control and freedom (Goodale et al., 2011).

In this article, we propose that any organizational system, with soft (tacit) and formal components, would necessarily need to allow achieving adaptability and alignment simultaneously, in order to act as the conduit for a positive TFL-CE linkage. Adaptability provides the freedom to respond to a changing environment, while alignment facilitates integration with established organizational systems. One influential framework that actually addresses this duality is Gibson and Birkinshaw's (2004) conceptualization of organizational ambidexterity, as a set of characteristics of the organization that facilitate the requisite balance between adaptability and alignment. Building upon the organizational ambidexterity concept (see below), we try to answer our main research question, namely 
whether organizational ambidexterity functions as a critical contextual pathway through which TFL will influence CE.

The pathway between TFL and CE through organizational ambidexterity that we envision suggests we should divide this long cascading process from TFL to $\mathrm{CE}$ into two stages, with different players in each stage. In the $1^{\text {st }}$ stage, moving upward from individual-leadership characteristics to organizational characteristics, TFL promotes organizational ambidexterity, as it aims to build the appropriate organizational systems to mobilize organizational members. Transformational leaders and their immediate subordinates, meaning the top management team (TMT), are the main driving forces in this stage. In the $2^{\text {nd }}$ stage, moving from organizational ambidexterity to desired organization-level behavior (in this case $\mathrm{CE}$ ), lower-ranked organizational members respond to their organizational context by discovering, screening, and pursuing selected initiatives. This stage thus relies on the activities of a larger spectrum of members, whereby we will focus on middle managers.

The $1^{\text {st }}$ stage emphasizes the development of a series of organizational systems that channel members' attention. The CEO as TFL-figure can affect organizational ambidexterity, but will also need to rely on the TMT to aid with instilling a CErelated vision throughout the organization (Waldman \& Yammarino, 1999). Here, we hypothesize that depending upon the situational context, and especially the level of environmental dynamism, particular TMT characteristics will influence the effectiveness of the CEO's transformational leadership in building organizational ambidexterity (Agle, Nagarajan, Sonnenfeld, \& Srinivasan, 2006).

The $2^{\text {nd }}$ stage is about how organizational members notice, select, and pursue latent entrepreneurial opportunities. In this stage, the perceived rules of the game will guide and constrain members' attention (Ren \& Guo, 2011). Besides organizational ambidexterity, as the soft side of organizational systems, specialized units (with specific structural or 'hard' characteristics, see infra) will offer varying levels of flexibility and allow members to attend to certain tasks while ignoring others. We hypothesize that organizational ambidexterity will interact with structural, organizational features, especially the organization's structural differentiation, to affect corporate entrepreneurship (see Figure 1). ${ }^{[1]}$ Our empirical evidence, based on a sample of 145 privately owned firms in China and using three sources of data (the CEO, the other TMT members, and middle managers), provides support for our hypotheses.

Our article augments the extant knowledge on the linkages between TFL and $\mathrm{CE}$ in three ways. First, different from the mainstream focus on employee empowerment and risk-taking as precursors of CE (e.g., Jung et al., 2003; Ling et al., 2008), we highlight the importance of managing contradictory tensions through organizational ambidexterity in order to facilitate CE. Mainstream thinking has tended to overlook the fact that CE typically co-exists with the management of established businesses. Embracing new businesses in established systems creates a particular challenge for organizational leaders trying to reconcile control and 


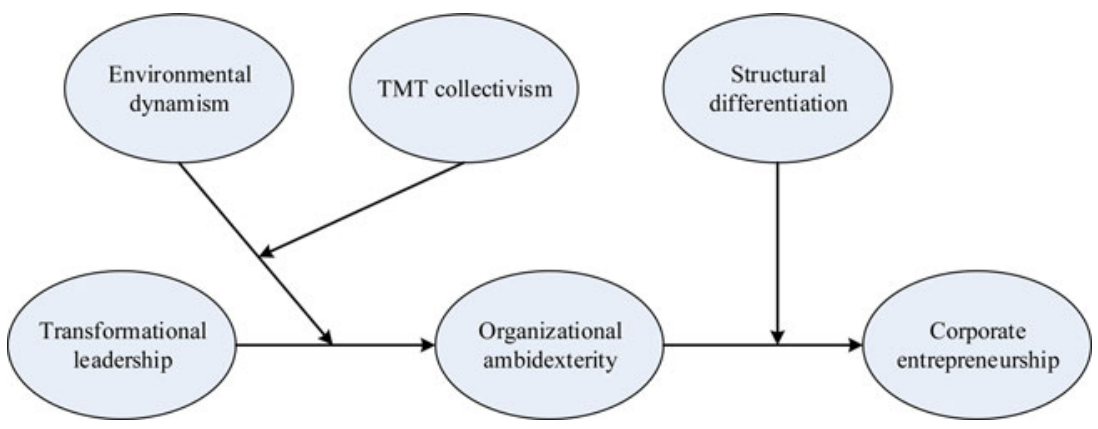

Figure 1. The moderated mediation approach for analyzing transformational leadership - Corporate entrepreneurship linkages

freedom (Garvin \& Levesque, 2006). We propose that organizational ambidexterity facilitates both adaptability and alignment, thereby acting as the conduit between TFL and CE. Our focus on this requisite balance, made possible through organizational ambidexterity, thus re-conceptualizes the role of TFL. TFL needs not only to remove constraints, so as to unleash innovative potential (e.g., Ling et al., 2008), but also to align innovative behaviors with organizational interests.

Second, we divide the cascading mechanism from TFL to CE into two stages and emphasize different players and contextual variables in each stage. This is quite different from the literature on either the mediation effects (e.g., Ling et al., 2008) or the boundary conditions involved between TFL and CE (e.g., Rosing, Frese, \& Bausch, 2011). The TFL-CE linkage involves a long cascading process and includes different players at different stages. Therefore, boundary conditions for different players are likely to differ. Our emphasis on different situational variables for different stages also sheds light on the inconsistent findings regarding the linkages between TFL and organizational innovation performance found in a limited number of empirical studies. One review lists only ten studies on the association between TFL and innovation performance at the organizational level, which range from positive to negative and from significant to non-significant (Rosing et al., 2011). Our moderated mediation models suggest that the causal mechanisms between TFL and organizational performance involve different players across different stages and should take into consideration different contingent factors in each stage.

\section{THEORETICAL BAGKGROUND AND HYPOTHESES}

\section{Antecedents of Corporate Entrepreneurship and Organizational Ambidexterity}

Firms with strong CE have the capacity to shift away (at least partly) from prior strategies, routines, and business models. CE requires the willingness and ability 
of organizational members to act upon their innate potential (Dess et al., 2003). Both external and internal environments have been shown to foster CE. For example, high firm failure rates in industry can be conducive to implementing a $\mathrm{CE}$ strategy. Internally, innovative practices are more likely in a work environment characterized by low bureaucracy and high decentralization of authority (Kuratko, Hornsby, \& Covin, 2014), and top-level managers promoting firm-level entrepreneurial activities (Ireland, Covin, \& Kuratko, 2009).

Earlier research on how to promote CE has tended to emphasize how organizational practices can facilitate innovation, but an emerging stream of research has started to argue that managers need to balance blanket facilitating versus controlling innovation (Garvin \& Levesque, 2006; Goodale et al., 2011). Traditional approaches to promote CE often faced the dilemma of choosing between the old and the new (Garvin \& Levesque, 2006). Existing businesses (i.e., the old) can hamper $\mathrm{CE}$ activities, and the lack of fit between existing product lines and new businesses can result in internal resistance. In contrast, a 'let a thousand flowers bloom' culture with an incoherent potpourri of CE activities often comes with a loss of strategic focus and operating discipline. Goodale et al. (2011), therefore, argue in favor of an 'operations control mechanism' to discipline CE, together with CE-facilitating organizational qualities (e.g., top management support, capacity to exercise discretion, and slack time availability). CE-facilitating qualities can remove constraints, while the operations control mechanism can guide and select appropriate CE opportunities. Organizational approaches that can balance between freedom and discipline are thus viewed as critical to successful CE.

Following the emerging perspective on the need to become Janus-like to mesh new businesses with established organizational systems (Garvin \& Levesque, 2006; Goodale et al., 2011), we propose that organizational ambidexterity, characterized by discipline, stretch, support, and reliability (Gibson \& Birkinshaw, 2004), represents such a balanced context between freedom and control, which can stimulate individual employees to pursue entrepreneurial initiatives. Organizational ambidexterity refers to a set of 'systems, processes, and beliefs that shape individual-level behaviors in an organization' (Gibson \& Birkinshaw, 2004: 212), and it combines both the firm's administrative systems and processes, and the underlying values and belief systems. Discipline refers to clear expectations and standards prevailing in an organization. Stretch refers to processes that push employees to pursue and achieve more ambitious goals. Support refers to help from the organization so that employees can pursue new ideas. Finally, reliability (which we think is more accurate than the elusive concept of trust) as an organizational ambidexterity component implies that entrepreneurial initiative is rewarded.

In Gibson and Birkinshaw's (2004) view, the four organizational ambidexterity components of discipline, stretch, support, and reliability are interdependent: the attributes of discipline and stretch drive employees to pursue ambitious goals aligned with organizational goals, and those of support and assumed reliability give employees the resources and freedom to do so. Organizational ambidexterity

(C) The Author(s), 2021. Published by Cambridge University Press on behalf of The International Association for Chinese Management Research 
signals to employees that they will have at least some flexibility and control over the tasks they are supposed to carry out. The discipline and stretch components prevent employees from ignoring organizational objectives and targets. Organizational ambidexterity thus melds discretion and formality (Garvin \& Levesque, 2006; Goodale et al., 2011) and is likely to be associated with higher overall levels of $\mathrm{CE}$.

\section{TFL and Organizational Ambidexterity}

The personal characteristics of leaders, such as their values and priorities, ultimately help determine their organizations' destiny (e.g., Hambrick \& Mason, 1984). A transformational leader is one who articulates a shared vision of the future, provides an appropriate role model, fosters group-oriented work, sets high expectations, stimulates followers intellectually, and provides a great deal of support to followers (Podsakoff et al., 1990). What this often means in practice, is that the prominent position of transformational CEOs allows them to influence the four organizational ambidexterity components (e.g., Berson, Oreg, \& Dvir, 2007). First, transformational CEOs can influence the discipline component of organizational ambidexterity. To foster discipline, they can imprint the firm with rules and routines they choose themselves and reframe strategies towards achieving goals such as growth and innovation. Second, in order to increase stretch, they can articulate a clear vision to guide employees' efforts towards entrepreneurial behaviors (Amabile, 1998), create a shared emphasis on entrepreneurship, creativity, and openness to new ideas (Berson et al., 2007), and change the organizational reward system to encourage employees to explore new fields. Third, in terms of support, they can allocate special funds to new projects, free up employees' time to engage in new initiatives, function as role models to stimulate critical thinking on organizational assumptions, etc. Fourth, in terms of assumed reliability of employees, they can make tangible processes such as the firm's reward system (a variable directly related to discipline) more consistent with intangible elements such as employees' beliefs, thereby creating an organizational context within which learning (including learning from failure) is truly valued.

Our research context in mainland China also supports the connection between TFL and organizational ambidexterity. Chinese enterprises often provide social welfare benefits to their employees; in many cases, Chinese employees tend to regard their work unit and their firm as a large family, and they look to their leaders for guidance and instruction (Li, Zhao, \& Begley, 2015). Due to social exchange norms, employees will typically feel obliged to take reciprocal actions to respond to transformational leadership behaviors.

The above discussion suggests that organizational ambidexterity mediates the relationship between TFL and CE. We therefore propose:

Hypothesis 1: Organizational ambidexterity mediates the positive relationship between TFL and CE.

(C) The Author(s), 2021. Published by Cambridge University Press on behalf of The International Association for Chinese Management Research 


\section{The Moderating Effects of Environmental Dynamism, TMT Collectivism, and Structural Differentiation}

Hypothesis 1 focuses on organizational characteristics operating as the pathway between TFL and CE. The latter outcome relies upon successful construction of organizational ambidexterity in the $1^{\text {st }}$ stage and the effective functioning of organizational ambidexterity in the $2^{\text {nd }}$ stage. Each stage involves different players, placed in different situations, and, therefore, likely to respond to their situational context in different ways.

First, organizational ambidexterity materializes, conditional upon the widespread receptivity from organizational members. Since transformational CEOs typically do not have direct contact with all their subordinates, they need close followers, i.e., the TMT members, to actively promote their vision, defend their actions, provide a model of followership for others, and motivate their subordinates to pursue ambitious goals (Galvin, Balkundi, \& Waldman, 2010; Waldman \& Yammarino, 1999). The receptivity of TMTs depends on their willingness to follow CEO directions. We, therefore, argue below that in the first stage, and depending on the external situational context, the relationship between TFL and organizational ambidexterity will be moderated by TMT collectivism. As regards this external situational context, we focus on the empirically often-considered variable of environmental dynamism.

Second, how organizational members select and attend to certain opportunities will be shaped by their perception of the rules of the game (Ren \& Guo, 2011), in the sense that formal and informal guiding principles, such as official tasks, rewards, and social status, will direct how members screen and choose entrepreneurial opportunities to pursue. Here, the structural feature of formal assignments of responsibilities and tasks will affect whether organizational ambidexterity will actually increase CE (see below).

\section{First Stage Moderation Effects: Environmental Dynamism and TMT Collectivism on Organizational Ambidexterity}

Environmental dynamism, collectivism, receptivity, and adaptive behavior. Various studies have suggested a positive association between environmental dynamism and group collectivism on the one hand, and receptivity to leaders' behavior and employees' perceived support for innovation on the other (e.g., Bradley, Shepherd, \& Wiklund, 2011; Goncalo \& Staw, 2006; Jung et al., 2003).

First, environmental dynamism refers to 'the rate of change and innovation in the industry as well as uncertainty and unpredictability of the actions of competitors and customers' (Miller \& Friesen, 1983: 222). A highly dynamic environment may lead employees to feel anxious, stressed, and lacking assurance about the future. In addition, highly dynamic environments offer more opportunities for employees to challenge the status quo and attempt to reach higher goals 
(Bradley et al., 2011). These environments are also more threatening, which creates additional stimuli for adaptation. In other words, highly dynamic environments create more receptivity to TFL efforts towards creating organizational ambidexterity.

Second, the trait of collectivism has also been linked to organizational members' receptivity to leadership and adaptive behaviors. Collectivism (as opposed to individualism) represents the extent to which a person believes that a collective's needs and obligations should take precedence over individual needs and desires, and the extent to which members of a group or organization wish to maintain harmonious, strong relationships with other members (Kim, Triandis, Kagitcibasi, Choi, \& Yoon, 1994). As collectivistic subordinates tend to be loyal, obedient, and have respect for their superiors (Bass, 1999), TFL's effect may be more enhanced with collectivistic followers.

Theoretical arguments and empirical findings have not been conclusive about the relationship between collectivism (vs. individualism) and adaptive behaviors (Goncalo \& Staw, 2006). One perspective is that collectivism is negatively related to adaptive behaviors. Since individuals with high scores on the collectivism scale value harmony and interdependence, they may view adaptive behaviors as deviant, and they may therefore avoid doing things differently from the group.

However, another perspective argues the opposite (e.g., Flynn \& Chatman, 2001): if persons who score high on collectivism accept intellectual stimulation as the collective's goal, collectivism can support high standards of performance targets and thus encourage adaptation. Here, supporting a CEO's TFL approach and her/his emphasis on achievement as a common goal meets the needs of highly collectivistic members for affiliation, cooperation, and team relationships (Schaubroeck, Lam, \& Cha, 2007). Transformational leaders may thus be more effective when surrounded by collectivistic TMT members.

The moderating effect of environmental dynamism and TMT collectivism. Recognizing that TMT collectivism could either support or inhibit followers' adaptive behavior, we argue below that the role of TMT collectivism in TFL's influence on organizational ambidexterity is likely to depend on environmental dynamism. In a dynamic environment characterized by rapid environmental change, employees may find it difficult to evaluate the impact of such change on their organization and to adopt an appropriate response, and they tend to look to their leaders for guidance and direction. Dynamic environments thus allow transformational CEOs greater latitude to influence the values of a large number of subordinates (Jansen, Vera, \& Crossan, 2009), thereby building a stronger alignment with both TFL's vision and strategic intent. Moreover, dynamic environments offer abundant opportunities for change and demand novel responses to threats. When transformational CEOs adopt new approaches to stimulate innovation, employees in dynamic environments are more likely to become engaged and to respond with novel ideas and 
increased effort (de Hogh, den Hartog, \& Koopman, 2005), thereby facilitating followers' adaptive behaviors.

The positively moderating effect of a dynamic environment may be amplified further if the other TMT members exhibit a high level of collectivism. A TMT with high scores on collectivism can help its transformational CEO to promote desired behaviour throughout the firm. It can support the $\mathrm{CEO}$ in inspiring employees, promoting collective purpose, and implementing processes to enhance organizational ambidexterity, both to increase employee acceptance of challenging goals and to provide support to attain such goals. Moreover, a TMT with higher scores on collectivism is also likely to be highly innovative in dynamic environments under the influence of a transformational CEO. If adaptation is the stated goal of a transformational CEO, then a TMT with higher scores on collectivism is more likely to accept such goals, to exhibit more entrepreneurial behaviour, and to engage in better execution. Such TMT approach can then encourage other employees to engage in higher levels of adaptive behavior and build the adaptation components of organizational ambidexterity.

In sharp contrast to the above, highly stable environments are associated with little uncertainty and offer few external inducements for change, whether in the form of opportunities or threats. Although individuals' idiosyncratic interpretations of environmental events may create unique opportunities (Sarason, Dean, \& Dillard, 2006), evaluating such singular opportunities and motivating employees to pursue them may be particularly challenging.

When TFL promotes alignment and adaption (i.e., organizational ambidexterity) in such a context, a TMT with a high score on collectivism may face considerable role conflicts and role ambiguities. On the one hand, members of such a TMT will emphasize harmony, and deviants will tend to be viewed as impediments to achieving group goals (Nemeth \& Staw, 1989). Conformity pressures may thus prevent TMT members from bringing up new perspectives, and the stable environment, not providing strong external inducements to justify strategy changes, will reinforce this tendency. On the other hand, the TMT members will be prone to collaborate with the transformational $\mathrm{CEO}$ and support challenging goals set by this CEO. As a result, the transformational CEO and the external environment will convey conflicting messages to the TMT members, which may lead to confusion among them. Collectivist TMTs thus tend to exhibit weak support for alignment and adaptation as desirable organizational characteristics.

If, on the contrary, TMT members are individualistic (i.e., earn low scores on collectivism), and are therefore more likely to generate new ideas themselves and to be more responsive to intellectual stimulation by the transformational CEO, no confusion as above arises. Since a transformational CEO also shows concern for individual needs, individualistic TMT members may be bolstered to help the CEO in implementing changes in organizational systems and processes to build organizational ambidexterity and promote CE. We thus propose:

(C) The Author(s), 2021. Published by Cambridge University Press on behalf of The International Association for Chinese Management Research 
Hypothesis 2: Environmental dynamism interacts with TMT collectivism to moderate the relationship between TFL and organizational ambidexterity: In a highly dynamic environment, higher TMT collectivism will strengthen this relationship, while in a highly stable environment, lower TMT collectivism will strengthen this relationship.

\section{Second Stage Moderation Effect: Structural Differentiation Inside the Organization}

Various authors have identified structural differentiation as an important determinant of organizational innovation/entrepreneurship (e.g., Burgers, Jansen, Van den Bosch, \& Volberda, 2009). Structural differentiation refers to 'the state of segmentation of the organizational system into subsystems, each of which tends to develop particular attributes in relation to the requirements posed by its relevant external environment' (Lawrence \& Lorsch, 1967: 3-4).

Structural differentiation can facilitate CE, e.g., as exemplified by the multidivisional company as compared to a conventional unitary form. It creates differences across organizational units with respect to product/market domains, mindsets, goal orientations, and functions. The boundaries created by structural differentiation may: (a) give independence to subunits in their operational functioning; (b) allow subunits to adapt their activities to fit their task environments; (c) give various levels of flexibility as to the strategic options managers can pursue; and (d) generate entrepreneurial activities (Simsek, Heavey, Veiga, \& Souder, 2009).

When organizations are more structurally differentiated already, organizational ambidexterity is unlikely to affect $\mathrm{CE}$ further. As the major advantages of structural differentiation are spatial separation to allow for experimental activities and local adaptation in different units, additional levels of flexibility from the adaptation component of organizational ambidexterity are unlikely to add anything to existing levels of independence and flexibility of work for employees. On the other hand, the alignment component of organizational ambidexterity may benefit $\mathrm{CE}$ by creating concerted efforts across highly differentiated units, but such alignment may then, in turn, hinder the flourishing of multiple mindsets across units, create role conflicts, and lessen the advantages of structural differentiation (Burgers et al., 2009). On balance, we propose that high levels of structural differentiation will eliminate any positive impact of organizational ambidexterity on $\mathrm{CE}$.

In contrast, if an organization has low structural differentiation, a positive effect of organizational ambidexterity on CE may materialize. Because of the absence of structural differentiation, subunits and lower-level employees have less flexibility in their operations, and employees may not feel empowered at the outset to experiment or pursue risky projects. Organizational ambidexterity, meaning a supportive behavioral context, where failure is viewed as a learning opportunity, and employees are assumed reliable, may then more than compensate for this. Moreover, employees in a highly integrated organization that lacks structural differentiation may better understand organizational goals, find it easier to 
connect organizational visions to their tasks, and incorporate organizational aspirations (Vaccaro, Jansen, Van Den Bosch, \& Volberda, 2012; Vera \& Crossan, 2004;). As a final point, the alignment component may not matter much, given existing high levels of integration across units.

It should be noted that our arguments are not in contradiction with current research on the positive impact of structural differentiation on innovation (e.g., Burgers et al., 2009). Precisely because of high levels of structural differentiation, having more organizational ambidexterity is unlikely to affect GE. We thus propose the following hypothesis:

Hypothesis 3: Higher structural differentiation inside the firm will weaken the relationship between organizational ambidexterity and $C E$.

As Hypothesis 1 suggests a mediation effect between TFL and CE through organizational ambidexterity, and Hypotheses 2 and 3 propose moderating effects in the two stages, these hypotheses taken together indicate the moderated mediating effects. Typically, when the environment is dynamic, the TMT is collectivistic, and structural differentiation is low, there will be a strong positive effect between TFL and CE through organizational ambidexterity. In contrast, in situations of a stable environment, an individualistic TMT, and high structural differentiation, there is a weak mediation effect. ${ }^{[2]}$

Hypothesis 4: Environmental dynamism, TMT collectivism, and structural differentiation together moderate the mediating process between TFL and CE through organizational ambidexterity.

\section{METHODS}

\section{Research Setting and Data Collection}

The empirical setting for the study is a large sample of privately-owned companies in mainland China. The initial sample included 700 enterprises selected from seven provinces in the database of the All-China Federation of Industry and Commerce (ACFIC), the largest association of privately-owned firms in mainland China. ACFIC supported this study and encouraged its members to participate in the survey conducted in 2010. The data came from three sources, namely the CEO, the other TMT members, and middle-level managers.

We designed three sets of questionnaires, namely for the $\mathrm{CEO}$, the other TMT members, and middle managers, respectively, with all constructs measured with established multi-item scales from prior research. We applied the back translation method and pre-tested the questionnaires with 20 EMBA students and 56 MBA students from the Institute of Psychology of the Chinese Academy of Sciences, a leading research institution located in Beijing.

In order to gain the cooperation of the respondents, we emphasized that none of the information provided would be released to their firm. We noted that the 
project was endorsed by ACFIC. We also hired three research assistants in each of the seven provincial branches of ACFIC to work on the project. These assistants phoned each CEO (or Chairman) to elicit their firm's participation. For the firms that agreed to participate, the CEOs and the research assistants jointly identified a coordinator (typically the CEO's assistant or an HR manager) and sent the questionnaires to this coordinator. Each CEO (or Chairman) provided the names of their TMT members and middle managers to the designated coordinator, who then distributed the survey to them. Each participant returned the survey in a sealed envelope to the coordinator, who then mailed responses to the research assistants.

As our survey included measures to be rated separately by the CEO, TMT members and middle managers, we only included firms in our analysis if there were responses from the CEO, at least two other TMT members, and representatives of middle-level management, leaving a final sample of 145 firms out of 700, i.e., a response rate of $20.7 \%$. The firms in this sample operate in multiple industries. On average, these firms had been in business for 15 years, employ 2,023 individuals, and have annual sales between RMB 10 million and 30 million.

On average, each TMT has 9.74 members (s.d. = 10.36), ranging from 3 to 15 members, including the CEO. Of the 651 TMT members (including the 145 CEOs and 506 other TMT members ${ }^{[3]}$ who provided usable and complete responses, $78 \%$ are male and $22 \%$ are female; $57.8 \%$ hold bachelor or graduate degrees. The average team member is 44 years old, has been with the current firm for 9.6 years, and has been a TMT member for 7 years. At the middle management level, we received an average of 13.66 responses from each firm. In total, there were 1,981 responses from middle managers, with $61.2 \%$ being male and $38.8 \%$ female. These middle managers have an average age of 35 .

\section{Measurement and Validation of Constructs}

Dependent variable: $C E$, as rated by the CEO. We used the 16-item scale from Ling et al. (2008) to measure the three dimensions of CE, including innovation (five items), venturing (five items), and strategic renewal (six items). The 16-item scale of CE was based on Zahra's (1996) 14-item scale with very minor modifications. We asked both the CEOs and the other TMT members to evaluate to what extent their firms had engaged in these activities in the past three years, but we applied the CEOs' responses for the regression analyses, as the CEOs are the most knowledgeable persons about corporate entrepreneurship in their firms.

To validate the measurement of $\mathrm{CE}$ in the more general context of privately owned firms in mainland China, we first conducted a confirmatory factor analysis (CFA) of CE based on the sample of the 530 TMT members of the firms not included in our sample, see footnote 3 , with the sixteen items loaded only on their related dimensions. This CFA led to the removal of five items with loadings below 0.50. ${ }^{[4]}$ Second, we kept three items for innovation, four items each for

(C) The Author(s), 2021. Published by Cambridge University Press on behalf of The International Association for Chinese Management Research 
venturing and renewal, and conducted a second-order CFA based on the sample of 145 CEOs. The results suggest an acceptable model fit $\left(\chi^{2}(39)=84.15, \mathrm{p}<0.001\right.$, $\mathrm{n}=145, \mathrm{CFI}=0.94, \mathrm{TLI}=0.96$, RMSEA $=0.07) .{ }^{[5]}$ All factor loadings are highly significant $(\mathrm{p}<0.001)$ (see Appendix I for details). We aggregated results over the three dimensions to obtain an overall $\mathrm{CE}$ score.

Independent variable: transformational leadership, as rated by the TMT members (not including the CEO). We used a 14-item measure (Kirkman, Chen, Farh, Chen, \& Lowe, 2009) of TFL, which is a shortened version of Podsakoff et al.'s 22-item scale (1990) that has been applied in prior research (Kirkman et al., 2009). The shortened version includes three items for the core transformational leadership behavior, three items for performance expectations, four items for individualized consideration, and four items for intellectual stimulation. We asked each TMT member (not including the CEO) to evaluate the CEO's TFL and aggregated TMT members' responses to obtain an overall score. To validate the measurement of TFL in our context of privately owned firms in mainland China, we again conducted a CFA based on the sample of the 530 TMT members who did provide data but who were excluded from the final regression analyses because their firms did not meet the required response threshold. We also conducted a second CFA at the individual level with our sample of 506 included TMT members (not counting the CEO). Both CFA results confirmed the measurement of TFL as a second-order construct with the above four dimensions (see below for details).

Moderator: Environmental dynamism, as rated by the TMT members (not including the CEO). We used four items from Waldman, Ramirez, House, and Puranam (2001) to measure environmental dynamism. All participating TMT members were asked to evaluate environmental dynamism. Both CFA results based on the sample of the 530 (excluded) TMT members and the sample of 506 (included) TMT members (see below for a detailed discussion of the second CFA results) confirmed the four-item measurement of environmental dynamism. We aggregated the TMT members' (not including the CEOs) responses to obtain an overall score (see below for details).

Moderator: TMT collectivism, as rated by the TMT members (not including the CEO). We used six items from Simsek et al. (2005) to measure TMT members' collectivism, with each item asking TMT members to evaluate the appropriateness of a particular behavior as a response in a specific situation. The CFA results based on the sample of 530 TMT members indicated that two items for collectivism obtained very low loadings (below 0.50). We thus removed these two items and retained the four remaining ones to conduct the second CFA (see below for a detailed discussion) to assess collectivistic orientation based on the sample of 506 TMT members. We averaged TMT members' responses across the four items to arrive at an individual-level scale score and then aggregated these outcomes 
across TMT members (not including the CEO) for the team-level score (see below for a justification of this aggregation).

Moderator: Structural differentiation, as rated by the TMT members (not including the CEO). We used a six-item scale from Jansen et al. (2009) to measure how organizations structure their organizational system into units with distinctive functions and product/market domains. The CFA results based on the sample of 530 TMT members indicated that two items for structural differentiation obtained very low loadings. ${ }^{[6]}$ We thus removed these two items and retained the four remaining ones to conduct the second CFA (see below for a detailed discussion) to assess structural differentiation based on the sample of 506 TMT members. We averaged TMT members' responses across the four items to arrive at an individual-level scale score and then aggregated across TMT members (not including the GEO) for the team-level score (see below for the CFA results and justification of this aggregation).

Construct validity and aggregation of variables rated by the TMT members. We followed a two-step procedure by conducting the first CFA based on the sample of 530 (excluded) TMT members and then running the second CFA to validate the measures with the sample of 506 (included) TMT members. In the second CFA, the constructs include a second-order transformational leadership measure with four dimensions, four items of environmental dynamism, four items of collectivistic orientation, and four items of structural differentiation. The CFA (see Appendix II) achieved a good model fit $\left(\chi^{2}(289)=891.68, \mathrm{p}<\right.$ $0.001, \mathrm{n}=506, \mathrm{CFI}=0.93, \mathrm{TLI}=0.91$, RMSEA $=0.06)$. According to Hair, Black, Babin, and Anderson (2009: 646), goodness of fit for a large sample size $(>250)$ with a large number of observed variables $(\geq 30)$ is subject to less strict criteria for evaluation, and CFI above 0.90 and RMSEA below 0.07 are indications of a good fit. All factor loadings are highly significant, with all construct reliabilities above the 0.70 benchmark, except for structural differentiation (0.66). Thus, the measures demonstrate good convergent validity and reliability.

As we intended to aggregate the individual-level data on transformational leadership, TMT collectivistic orientation, environmental dynamism, and structural differentiation to the team level, we needed to examine statistically the similarity across individual responses. We calculated intra-class correlation coefficients (ICGs; Bliese, 2000). ICG(1) indicates the ratio of between-group to total variance. Aggregation to the team level demands ICC(1) to be positive and the corresponding F value to be statistically significant (Kenny \& La Voie, 1985). ICG(2) represents the reliability of average group perceptions, and a cutoff value of 0.70 is again often used for aggregation (LeBreton \& Senter, 2008). The values obtained are as follows. For transformational leadership:0.72 (ICC1), 0.93 (ICC2); for collectivistic orientation, 0.62 (ICC1), 0.89 (ICC2); for environmental dynamism,

(C) The Author(s), 2021. Published by Cambridge University Press on behalf of The International Association for Chinese Management Research 
0.74 (ICC1), 0.93 (ICC2); for structural differentiation, 78 (ICC1), 0.94 (ICC2). The results justify aggregating responses to the TMT level (Bliese, 2000).

Mediator: Organizational ambidexterity. We used the 16-item scale from Gibson and Birkinshaw (2004) to measure organizational ambidexterity characterized by discipline, stretch, support, and reliability. Although organizational ambidexterity was initially conceptualized as consisting of four distinct but interdependent dimensions, Gibson and Birkinshaw found a two-factor structure in their empirical study, with the two factors being highly correlated $(r=0.82, p<0.01)$ (Gibson \& Birkinshaw, 2004: 220). The high correlation between the two factors suggested either a second-order construct or a single factor (Brown, 2006). As there has not been any validation of the constructs, we conducted three analyses to further develop the structure. First, since we only retained firms with responses from the CEO, at least two other TMT members, and a set of middle-level managers for the main analyses, we had a remaining set of responses of 1,939 middle managers who had not yet been included in the empirical analysis. An exploratory factor analysis (EFA), with the sample based on maximum likelihood extraction, oblique rotation, and the screen test, revealed a four-factor structure. We then conducted a CFA with the 1,981 middle-managers who were included in the study, and this showed a good model fit with the data $\left(\chi^{2}(73)=686.99, \mathrm{p}<0.001, \mathrm{n}=1,981\right.$, $\mathrm{CFI}=0.96$, TLI $=0.95$, RMSEA $=0.065$, see Appendix III for the details of the CFA results). We, therefore, aggregated the four dimensions to obtain an overall organizational ambidexterity score.

As regards aggregating the individual perceptions on organizational ambidexterity, we calculated ICGs and obtained the following results: 0.45 (ICC1), 0.91 (ICC2). These results justify aggregating individual responses to the firm-level so as to obtain an overall score for organizational ambidexterity.

Control variables. We controlled for the CEO-level, firm-level, and TMT-level demographic variables. As founders may imprint new ventures (Fauchart \& Gruber, 2011), we control CEOs' founder position ( $1=$ founder, $0=$ others). Small firms may allow for more discretion (Wei \& Ling, 2015), and firm scales pose various challenges to new business creation (Sathe, 2003), so we control firm age and size. Firm size was measured with the logarithm of the number of employees, and firm age as the number of years since the establishment of the firm. As the skills, knowledge, and background of TMTs influence strategic decisions and CE, we follow existing literature (Srivastava \& Lee, 2005) and control major TMT demographic variables (education, tenure, and heterogeneity). TMT size was measured as the average of the number of TMT members reported by each TMT member. Company tenure was measured as the mean number of years that each TMT member had worked in the company; TMT tenure was measured as the mean number of years that each respondent has been a TMT member, and TMT average education was measured as the mean educational 
level of the TMT members. We measured education level on a 6-point scale $(1=$ masters or above, $2=$ undergraduate, $3=$ college, $4=$ technical secondary school, $5=$ senior high, $6=$ junior high). Company tenure diversity and educational diversity were measured by their variance, respectively. Functional diversity was computed with Blau's index (Simons, Pelled, \& Smith, 1999). We asked respondents to indicate their main functional background, including finance and accounting, human resources, general management, marketing, operations, research, and development, or strategic planning. Gender diversity was measured as the percentage of female respondents in a TMT.

\section{RESULTS}

Table 1 presents means, standard deviations, and correlations for the variables. The Kolmogorov-Smirnov tests support the univariate normality assumption; the variance inflation factors (VIF) are below 5, indicating that multicollinearity is not a problem (Hair et al., 2009). ${ }^{[7]}$

We applied the bootstrapping method to generate confidence intervals (CIs) for the proposed mediation and moderated mediation processes (Hayes, 2013). We applied an SPSS macro developed by Hayes (2013). ${ }^{[8]}$ To examine the mediation process proposed in Hypothesis 1, we followed the procedures in Hayes (2013). We conducted hierarchical regression analyses to test Hypotheses 2 and 3. Given significant interaction effects in Hypotheses 2 and 3, we generated the CIs at various values of environmental dynamism, collectivism, and structural differentiation to test Hypothesis 4.

Hypothesis 1 proposed that in general terms, organizational ambidexterity mediates the relationship between TFL and CE. The bootstrapping result based on 20,000 bootstrap samples shows that the 95\% CIs are between -0.016 and 0.1743 (see indirect effects, Table 2). Because zero is contained in the CIs, Hypothesis 1 was not supported. Hypothesis 2 suggested that TFL, environmental dynamism, and TMT collectivism interact to affect organizational ambidexterity. The three-way interaction is significant $(\mathrm{t}=2.68$, Table 3), supporting Hypothesis 2 . We present the effects in Figure 2, with the scatterplot showing the dispersion of the moderators (Greve, 2018; Levine, 2018; Välikangas, 2018). The three-way interaction has a relatively small effect size (effect size: Cohen's $f^{2}=0.06$, see Cohen, 1988), but the significance for practice is high, with TMT collectivism having its moderating effect reversed depending upon the presence of a stable versus dynamic environment. When the environment is dynamic, the effect of TFL on organizational ambidexterity changes from non-significant $(0.37, \mathrm{t}=1.96)$ at low levels of TMT collectivism to significant and positive at high levels of TMT collectivism $(0.70, \mathrm{t}=5.02)$, demonstrating an increasingly positive effect with TMT collectivism. When the environment is stable, the effect of TFL on organizational ambidexterity changes from significant and positive $(0.36, \mathrm{t}=2.95)$ at low levels of 
Table 1. Descriptive statistics: Means, standard deviations, and correlations between variables

\begin{tabular}{|c|c|c|c|c|c|c|c|c|c|c|c|c|c|c|c|c|c|}
\hline & Mean & $S D$ & 1 & 2 & 3 & 4 & 5 & 6 & 7 & 8 & 9 & 10 & 11 & 12 & 13 & 14 & 15 \\
\hline $\begin{array}{l}\text { 1. Transformational } \\
\text { leadership }\end{array}$ & 5.56 & 0.73 & 1.00 & & & & & & & & & & & & & & \\
\hline $\begin{array}{l}\text { 2. Organizational } \\
\text { ambidexterity }\end{array}$ & 5.31 & 0.72 & $0.397 * *$ & 1.00 & & & & & & & & & & & & & \\
\hline $\begin{array}{l}\text { 3. Corporate } \\
\text { entrepreneurship }\end{array}$ & 5.17 & 0.98 & $0.366 * *$ & $0.224 * *$ & 1.00 & & & & & & & & & & & & \\
\hline $\begin{array}{l}\text { 4. Environmental } \\
\text { dynamism }\end{array}$ & 4.04 & 1.01 & -0.05 & $-0.275^{* *}$ & 0.07 & 1.00 & & & & & & & & & & & \\
\hline 5. TMT Collectivism & 4.02 & 0.91 & 0.05 & -0.09 & $0.188 *$ & 0.440 ** & 1.00 & & & & & & & & & & \\
\hline $\begin{array}{l}\text { 6. Structural } \\
\text { differentiation }\end{array}$ & 4.74 & 0.74 & $0.261 * *$ & 0.13 & $0.330 * *$ & $0.454 * *$ & $0.323 * *$ & 1.00 & & & & & & & & & \\
\hline 7. Firm age & 14.58 & 9.74 & 0.07 & 0.07 & -0.04 & -0.05 & -0.01 & -0.15 & 1.00 & & & & & & & & \\
\hline $\begin{array}{l}\text { 8. Firm size (no. of } \\
\text { employees) }\end{array}$ & 2023.25 & 9277.64 & 0.03 & 0.15 & 0.04 & $-0.192^{*}$ & -0.16 & 0.05 & 0.14 & 1.00 & & & & & & & \\
\hline 9. Company tenure & 9.11 & 5.91 & 0.06 & 0.06 & -0.06 & -0.01 & -0.02 & -0.16 & $0.752 * *$ & $0.166^{*}$ & 1.00 & & & & & & \\
\hline 10. TMT size & 9.74 & 10.36 & -0.08 & -0.08 & -0.09 & 0.13 & 0.08 & 0.04 & $0.166^{*}$ & 0.10 & 0.07 & 1.00 & & & & & \\
\hline 11. TMT tenure & 6.15 & 3.77 & 0.00 & -0.07 & -0.02 & 0.11 & 0.05 & -0.06 & $0.380^{* *}$ & 0.01 & $0.641 * *$ & 0.10 & 1.00 & & & & \\
\hline $\begin{array}{l}\text { 12. TMT average } \\
\text { education }\end{array}$ & 2.55 & 0.87 & 0.05 & $0.177^{*}$ & 0.00 & -0.03 & -0.06 & -0.02 & -0.01 & -0.15 & 0.00 & -0.14 & 0.03 & 1.00 & & & \\
\hline $\begin{array}{l}\text { 13. TMT functional } \\
\text { diversity }\end{array}$ & 0.53 & 0.23 & -0.16 & -0.12 & -0.04 & 0.00 & -0.05 & 0.09 & -0.03 & 0.05 & -0.01 & 0.05 & 0.07 & -0.07 & 1.00 & & \\
\hline 14. TMT sex diversity & 0.26 & 0.28 & -0.09 & 0.03 & -0.01 & $0.305^{* *}$ & $0.186^{*}$ & 0.07 & 0.04 & -0.10 & -0.07 & -0.03 & -0.04 & 0.16 & $-0.219 * *$ & 1.00 & \\
\hline $\begin{array}{l}\text { 15. Company tenure } \\
\text { diversity }\end{array}$ & 0.46 & 0.38 & -0.03 & -0.01 & 0.07 & -0.05 & -0.03 & 0.00 & -0.01 & -0.09 & -0.331 ** & -0.08 & $-0.401 * *$ & 0.01 & -0.09 & 0.07 & 1.00 \\
\hline 16. Founder & 0.49 & 0.50 & 0.13 & -0.02 & 0.06 & -0.09 & -0.02 & -0.04 & $-0.31^{* *}$ & 0.03 & $-0.16^{* *}$ & 0.05 & 0.12 & 0.13 & 0.08 & $-0.17^{*}$ & $-0.17^{*}$ \\
\hline
\end{tabular}

Notes: $\mathrm{N}=145 . * * \mathrm{p}<0.01 ; * \mathrm{p}<0.05$. 
Table 2. Testing of hypothesis 1: The mediation model in figure 1

TFL on CE (rated by the CEO) via Organizational ambidexterity

\begin{tabular}{|c|c|c|c|c|c|c|c|c|c|c|c|}
\hline \multicolumn{4}{|c|}{$\begin{array}{c}\text { Step } 1 \text { (DV: corporate entrepreneurship, } \\
\text { rated by the CEO) }\end{array}$} & \multicolumn{4}{|c|}{$\begin{array}{c}\text { Step } 2 \text { (DV: Organizational } \\
\text { ambidexterity) }\end{array}$} & \multicolumn{4}{|c|}{$\begin{array}{c}\text { Step } 3 \text { (DV: corporate entrepreneurship, } \\
\text { rated by the CEO) }\end{array}$} \\
\hline coeff & se & $t$ & $p$ & coeff & se & $t$ & $p$ & coeff & se & $t$ & $p$ \\
\hline 0.51 & 0.11 & 4.49 & 0.00 & 0.38 & 0.08 & 4.72 & 0.00 & 0.45 & 0.12 & 3.61 & 0.00 \\
\hline 0.00 & 0.01 & -0.32 & 0.75 & 0.00 & 0.01 & -0.15 & 0.88 & 0.00 & 0.01 & -0.27 & 0.79 \\
\hline 0.00 & 0.00 & 0.69 & 0.49 & 0.00 & 0.00 & 2.08 & 0.04 & 0.00 & 0.00 & 0.46 & 0.64 \\
\hline-0.01 & 0.03 & -0.51 & 0.61 & 0.01 & 0.02 & 0.45 & 0.65 & -0.02 & 0.03 & -0.57 & 0.57 \\
\hline-0.01 & 0.01 & -0.66 & 0.51 & 0.00 & 0.01 & -0.38 & 0.70 & -0.01 & 0.01 & -0.66 & 0.51 \\
\hline 0.02 & 0.03 & 0.81 & 0.42 & -0.02 & 0.02 & -0.99 & 0.32 & 0.03 & 0.03 & 0.85 & 0.40 \\
\hline-0.03 & 0.10 & -0.30 & 0.77 & 0.15 & 0.07 & 2.20 & 0.03 & -0.05 & 0.10 & -0.47 & 0.64 \\
\hline 0.10 & 0.36 & 0.28 & 0.78 & -0.18 & 0.26 & -0.71 & 0.48 & 0.19 & 0.37 & 0.52 & 0.61 \\
\hline 0.10 & 0.30 & 0.33 & 0.74 & 0.08 & 0.22 & 0.37 & 0.71 & 0.12 & 0.31 & 0.39 & 0.70 \\
\hline 0.22 & 0.25 & 0.88 & 0.38 & -0.05 & 0.17 & -0.31 & 0.76 & 0.22 & 0.25 & 0.90 & 0.37 \\
\hline \multirow[t]{2}{*}{-0.02} & 0.18 & -0.12 & 0.91 & -0.10 & 0.13 & -0.80 & 0.43 & 0.02 & 0.19 & 0.09 & 0.93 \\
\hline & & & & & & & & 0.15 & 0.13 & 1.23 & 0.22 \\
\hline
\end{tabular}

Organizational ambidexterity

$\begin{array}{ccc}0.16 & 0.23 & 0.16 \\ 2.16 & 3.53 & 2.08 \\ 11 & 11 & 12 \\ 129 & 129 & 128 \\ 0.02 & 0 & 0.02\end{array}$

0

0.02

Conditional indirect effect(s) of transformational leadership on corporate entrepreneurship (rated by the CEO) via organizational ambidexterity

$\begin{array}{lcccc} & \text { Effect } & \text { Boot SE } & \text { BootLLCI } & \text { BootULCI }\end{array}$

Notes: $\mathrm{N}=141$. Listwise deletion applied. BootLLCI refers to the lower bound bootstarpping confidence intervals, and BootULCI refers to the upper bound bootstrapping confidernce intervals. Number of bootstrap samples for bias corrected bootstrap confidence intervals: 20, 000. Level of confidence for all confidence intervals in output: .95. We keep four decimal digits for the bootstrap results because some bootstrap values may be quite close to zero. 
Table 3. Testing of hypothesis 2

\begin{tabular}{|c|c|c|c|c|c|c|c|c|c|c|c|c|}
\hline & \multicolumn{12}{|c|}{ DV: Organizational ambidexterity } \\
\hline & coeff & se & $t$ & $p$ & coeff & se & $t$ & $p$ & coeff & se & $t$ & $p$ \\
\hline Transformational leadership & 0.39 & 0.08 & 5.03 & 0.00 & -0.25 & 0.38 & -0.65 & 0.52 & 3.87 & 1.58 & 2.45 & 0.02 \\
\hline Firm age & -0.01 & 0.01 & -0.68 & 0.50 & 0.00 & 0.01 & -0.07 & 0.95 & 0.00 & 0.01 & -0.42 & 0.67 \\
\hline Firm size & 0.00 & 0.00 & 1.56 & 0.12 & 0.00 & 0.00 & 2.12 & 0.04 & 0.00 & 0.00 & 2.56 & 0.01 \\
\hline TMT company tenure & 0.01 & 0.02 & 0.66 & 0.51 & 0.00 & 0.02 & 0.16 & 0.87 & 0.00 & 0.02 & 0.10 & 0.92 \\
\hline TMT size & 0.00 & 0.01 & 0.21 & 0.83 & 0.00 & 0.01 & 0.56 & 0.58 & 0.00 & 0.01 & 0.57 & 0.57 \\
\hline TMT tenure & -0.01 & 0.02 & -0.73 & 0.47 & -0.02 & 0.02 & -0.97 & 0.33 & -0.01 & 0.02 & -0.70 & 0.48 \\
\hline TMT average education & 0.14 & 0.07 & 2.09 & 0.04 & 0.10 & 0.06 & 1.55 & 0.12 & 0.11 & 0.06 & 1.77 & 0.08 \\
\hline TMT functional diversity & -0.10 & 0.25 & -0.42 & 0.68 & 0.13 & 0.24 & 0.53 & 0.59 & 0.14 & 0.23 & 0.60 & 0.55 \\
\hline TMT sex diversity & 0.32 & 0.22 & 1.50 & 0.14 & 0.35 & 0.20 & 1.75 & 0.08 & 0.35 & 0.20 & 1.80 & 0.07 \\
\hline TMT company tenure diversity & -0.06 & 0.17 & -0.34 & 0.74 & -0.14 & 0.16 & -0.90 & 0.37 & -0.14 & 0.15 & -0.88 & 0.38 \\
\hline Founder & -0.16 & 0.13 & -1.25 & 0.21 & -0.08 & 0.12 & -0.65 & 0.52 & -0.12 & 0.12 & -0.99 & 0.33 \\
\hline Envionmental dynamism & -0.20 & 0.06 & -3.19 & 0.00 & -0.69 & 0.46 & -1.49 & 0.14 & 5.27 & 2.27 & 2.32 & 0.02 \\
\hline Collectivism & 0.03 & 0.07 & 0.39 & 0.70 & 1.25 & 0.64 & 1.97 & 0.05 & 7.29 & 2.34 & 3.12 & 0.00 \\
\hline Transformational leadership * environmental dynamism & & & & & 0.24 & 0.07 & 3.19 & 0.00 & -0.79 & 0.39 & -2.03 & 0.04 \\
\hline Transformational leadership * TMT collecivism & & & & & -0.07 & 0.10 & -0.73 & 0.46 & -1.10 & 0.40 & -2.78 & 0.01 \\
\hline Environmental dynamism * TMT collectivism & & & & & -0.21 & 0.06 & -3.60 & 0.00 & -1.68 & 0.55 & -3.04 & 0.00 \\
\hline Transformational leadership * environmental dynamism * TMT collectivism & & & & & & & & & 0.25 & 0.09 & 2.68 & 0.01 \\
\hline R-sq change & 0.3 & & & & 0.10 & & & & 0.03 & & & \\
\hline F change & 4.15 & & & & 7.12 & & & & 7.17 & & & \\
\hline Sig. F change & 0 & & & & 0.00 & & & & 0.01 & & & \\
\hline $\mathrm{R}-\mathrm{sq}$ & 0.3 & & & & 0.40 & & & & 0.43 & & & \\
\hline $\mathrm{F}$ & 4.15 & & & & 5.19 & & & & 5.55 & & & \\
\hline $\mathrm{dfl}$ & 13 & & & & 3 & & & & 17 & & & \\
\hline $\mathrm{df} 2$ & 128 & & & & 125 & & & & 124 & & & \\
\hline $\mathrm{p}$ & 0 & & & & 0 & & & & 0 & & & \\
\hline
\end{tabular}

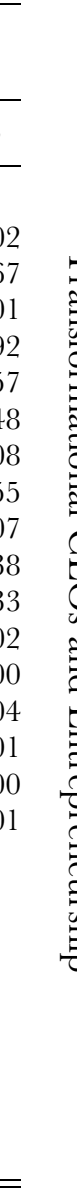

Notes: $\mathrm{N}=142$. Listwise deletion applied. 


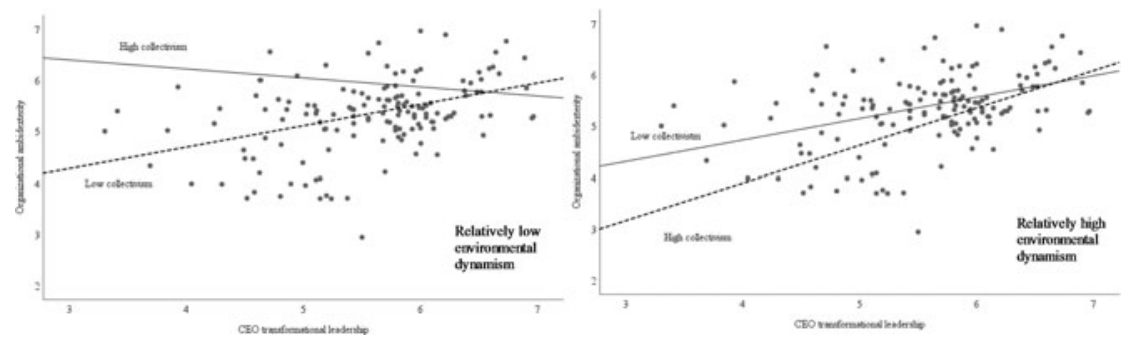

Figure 2. Moderation effects of TFL, environmental dynamism, and TMT collectivism on organizational ambidexterity

TMT collectivism to non-significant and negative at high levels of TMT collectivism $(-0.19, \mathrm{t}=-1.01)$, exhibiting a decreasingly positive effect with TMT collectivism.

Hypothesis 3 proposed the interaction effect of organizational ambidexterity and structural differentiation on CE. The two-way interaction is significant $(\mathrm{t}=$ -2.16, Table 4), supporting Hypothesis 3 (effect size: Cohen's $\mathrm{f}^{2}=0.04$; small effect size, see Cohen, 1988). Further probing (cf. Figure 3 with the scatter plot for the stylized effects) indicates that the effect of organizational ambidexterity on $\mathrm{CE}$ changes from significant and positive $(0.28, \mathrm{t}=2.07)$ at low levels of structural differentiation to non-significant and negative at high levels of structural differentiation $(-0.10, \mathrm{t}=-0.61)$.

Given significant interaction effects among transformational leadership, environmental dynamism, and TMT collectivism $(\mathrm{t}=2.68$, Table 3$)$, and between organizational ambidexterity and structural differentiation $(\mathrm{t}=-2.16$, Table 4), we followed Hayes (2013) to probe the moderated mediation effects, as shown in Table 5 (see Cole, Walter, and Bruch (2008) for similar applications of procedures of testing moderated mediation). Our results demonstrate that in situations when the environment is dynamic and structural differentiation is low, TFL has an increasingly positive effect on CE through organizational ambidexterity, as the TMT becomes more collectivistic (i.e., there is an increasingly positive moderating effect of TMT collectivism in this situation); when the environment is stable and structural differentiation is low, TFL has a positive effect on CE through organizational ambidexterity, only at low levels of TMT collectivism (i.e., more individualistic TMT members will strengthen the mediating process). Hypothesis 4 was thus supported.

\section{DISGUSSION}

We have tested a new, moderated mediation approach to assess the interdependencies among multiple levels of management in stimulating CE. We have highlighted not only the importance of duality of organizational context in the TFL-CE linkage but also the required internal and external situational factors in the process that leads from TFL to organizational context and finally to CE. 
Table 4. Testing of hypothesis 3

\begin{tabular}{|c|c|c|c|c|c|c|c|c|}
\hline & \multicolumn{8}{|c|}{$D V$ : corporate entrepreneurship, rated by the $C E O)$} \\
\hline & coeff & se & $t$ & $p$ & coeff & se & $t$ & $p$ \\
\hline Transformational leadership & 0.34 & 0.13 & 2.70 & 0.01 & 0.39 & 0.13 & 3.09 & 0.00 \\
\hline Firm age & 0.00 & 0.01 & 0.04 & 0.97 & 0.00 & 0.01 & -0.04 & 0.97 \\
\hline Firm size & 0.00 & 0.00 & 0.24 & 0.81 & 0.00 & 0.00 & 0.45 & 0.67 \\
\hline TMT company tenure & -0.01 & 0.03 & -0.33 & 0.74 & -0.01 & 0.03 & -0.36 & 0.72 \\
\hline TMT size & -0.01 & 0.01 & -0.93 & 0.36 & 0.00 & 0.01 & -0.60 & 0.55 \\
\hline TMT tenure & 0.02 & 0.03 & 0.64 & 0.52 & 0.01 & 0.03 & 0.43 & 0.67 \\
\hline TMT average education & -0.05 & 0.10 & -0.48 & 0.63 & -0.02 & 0.09 & -0.24 & 0.81 \\
\hline TMT functional diversity & 0.00 & 0.36 & 0.01 & 0.99 & 0.03 & 0.36 & 0.08 & 0.94 \\
\hline TMT sex diversity & 0.01 & 0.30 & 0.05 & 0.96 & 0.06 & 0.3 & 0.21 & 0.84 \\
\hline $\begin{array}{l}\text { TMT company tenure } \\
\text { diversity }\end{array}$ & 0.23 & 0.24 & 0.95 & 0.34 & 0.19 & 0.24 & 0.79 & 0.43 \\
\hline Founder & 0.10 & 0.18 & 0.52 & 0.60 & 0.08 & 0.18 & 0.47 & 0.64 \\
\hline $\begin{array}{l}\text { Organizational } \\
\text { ambidexterity }\end{array}$ & 0.14 & 0.12 & 1.13 & 0.26 & 1.34 & 0.57 & 2.35 & 0.02 \\
\hline Structural differentiation & 0.32 & 0.12 & 2.79 & 0.01 & 1.67 & 0.63 & 2.64 & 0.01 \\
\hline $\begin{array}{l}\text { Organizational ambidexter- } \\
\text { ity * Structural } \\
\text { differentiation }\end{array}$ & & & & & -0.26 & 0.12 & -2.16 & $\mathbf{0 . 0 3}$ \\
\hline R-sq change & 0.21 & & & & 0.03 & & & \\
\hline F change & 2.62 & & & & 4.67 & & & \\
\hline Sig. F change & 0.00 & & & & 0.03 & & & \\
\hline R-sq & 0.21 & & & & 0.24 & & & \\
\hline $\mathrm{F}$ & 2.62 & & & & 2.84 & & & \\
\hline df1 & 13 & & & & 14 & & & \\
\hline df2 & 127 & & & & 126 & & & \\
\hline $\mathrm{P}$ & 0.003 & & & & 0.001 & & & \\
\hline
\end{tabular}

Notes: $\mathrm{N}=141$. Listwise deletion applied.

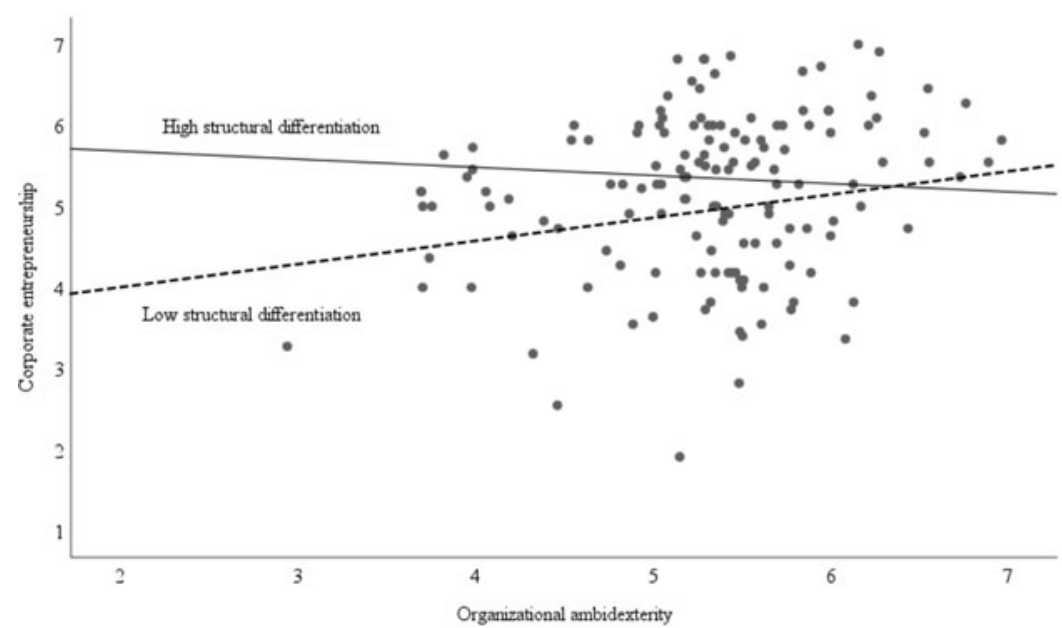

Figure 3. Moderation effects of structural differentiation and organizational ambidexterity on CE

(C) The Author(s), 2021. Published by Cambridge University Press on behalf of The International Association for Chinese Management Research 
Table 5. Testing of hypothesis 4: Indirect effects of TFL on CE

Conditional indirect effect(s) of TFL on CE at values of environmental dynamism, TMT collectivism, and structural differentiation via Organizational ambidexterity TMT

Mediator

Environmental dynamism

collectivism

Structural differentiation

Effect

Boot SE

$\mathbf{0 . 1 2 0 2}$

0.0392

0.0717

B

Organizational ambidexterity

Organizational ambidexterity

$\begin{array}{ll}\text { low low } & \text { low } \\ \text { low }\end{array}$

Organizational ambidexterity

low

low

low

Organizational ambitexterity

low

Organizational ambidexterity

Organizational ambidexterity

Organizational ambidexterity

Organizational ambidexterity

Organizational ambidexterity

Organizational ambidexterity

Organizational ambidexterity

Organizational ambidexterity

Organizational ambidexterity

Organizational ambidexterity

Organizational ambidexterity

Organizational ambidexterity

Organizational ambidexterity

Organizational ambidexterity

Organizational ambidexterity

Organizational ambidexterity

low

low

low

medium

$\begin{array}{ll}\text { low } & \text { low } \\ \text { low } & \text { medium }\end{array}$

low high

medium

medium

medium

medium

high

high

medium

medium

medium

medium

medium

medium

medium

medium

high

high

high

Organizational ambidexterity

high

high

high

low

low

low

$-0.0418$

0.0438

0.0348

0.0113

0.052

0.0468

0.02

$-0.0121 \quad 0.0259$

low

medium

$-0.0507$

0.0259
0.0874

high

$-0.0165$

0.0415

0.0176

0.0468

low

0.0653

0.039

0.042

$\mathbf{0 . 0 9 9 2}$

0.0522

medium

medium high

high

high

high

low

low

0.0323

$\mathbf{0 . 0 5 7 3}$

$-0.0345$

0.034

low

medium

high

low

0.0257

0.0694

$-0.0275$

0.1189

0.0329

medium

low

high

medium low

0.0929

0.0498

$-0.0414$

0.0645

0.1637

0.088

0.0534

0.0569

high

$-0.057$

0.0741

BootLLCI

BootULCI

medium

high

$-0.057$

0.018

0.3248

$-0.0213$

0.1638

$-0.1787$

0.0401

$\begin{array}{ll}-0.0338 & 0.1674\end{array}$

$\begin{array}{ll}-0.0107 & 0.0797\end{array}$

$-0.0968 \quad 0.0159$

$\begin{array}{ll}-0.2568 & 0.1068\end{array}$

$\begin{array}{ll}-0.1628 & 0.0277\end{array}$

$\begin{array}{ll}-0.0426 & 0.1713\end{array}$

0.026

0.2949

$-0.0326$

$-0.156$

0.1402

$\begin{array}{ll}\mathbf{0} & \mathbf{0 2 4 5} \\ -0.0264 & 0.1137\end{array}$

$\begin{array}{ll}-0.1379 & 0.0385\end{array}$

$-0.0048 \quad 0.2962$
-0.014

$-0.014$

0.1343

$-0.1627$

0.0003

0.0216

$-0.0304$

$-0.2108$

$\mathbf{0 . 0 3 6 9} \quad \mathbf{0 . 3 8 7 7}$

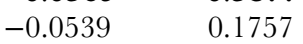

0.0781 
Table 5. Continued

Conditional indirect effect(s) of TFL on CE at values of environmental dynamism, TMT collectivism, and structural differentiation via Organizational ambidexterity

\begin{tabular}{llllllcc}
\hline Mediator & Environmental dynamism & $\begin{array}{l}\text { TMT } \\
\text { collectivism }\end{array}$ & Structural differentiation & Effect & Boot SE & BootLLCI & BootULCI \\
\hline Organizational ambidexterity & high & high & $\mathbf{l o w}$ & $\mathbf{0 . 2 0 8 5}$ & $\mathbf{0 . 1 0 4 7}$ & $\mathbf{0 . 0 4 5 6}$ & $\mathbf{0 . 4 6 9}$ \\
Organizational ambidexterity & high & high & medium & 0.068 & 0.0703 & -0.0687 & 0.2149 \\
Organizational ambidexterity & high & high & high & -0.0726 & 0.0912 & -0.2578 & 0.1015 \\
\hline \hline
\end{tabular}

Organizational ambidexterity

high

high

high

Notes: $\mathrm{N}=141$. Listwise deletion applied. Number of bootstrap samples for bias corrected bootstrap confidence intervals: 20, 000. Level of confidence for all confidence intervals in output: .95 Significant results are highlighted in bold. Low, medium, and high levels of environmental dynamism are at the values of 4.039 (mean), 3.0422 (1 sd below the mean), and 5.0359 ( 1 sd above the mean).

Low, medium, and high levels of TMT collectivism are at the values of 4.0226 (mean), 3.1284 (1 sd below the mean), and 4.9167 ( 1 sd above the mean). Low, medium, and high levels of structural differentiation are at the values of 4.7366 (mean), 3.9975 ( 1 sd below the mean), and 5.4756 ( 1 sd above the mean). 
A first critical feature of our study, beyond the technical results, is that our approach differs significantly from the dominant perspective in the literature on transformational leadership. The dominant view is that elements such as 'empowering', 'risk-taking', and an 'innovative organizational context' are the crucial mediators between TFL and CE (e.g., Jung et al., 2003; Ling et al., 2008). In sharp contrast with this ill-conceived view, we adopt the emerging proposition that $\mathrm{CE}$ requires reconciling the needs of established and new businesses (Garvin \& Levesque, 2006; Goodale et al., 2011). A fundamental challenge when examining the connection between TFL and CE is, therefore, to uncover how organizations manage the conflicts - and overcome the tensions - between 'established' and 'new'. We have found that organizational ambidexterity, which facilitates both adaptability and alignment, effectively connects TFL and CE, but subject to boundary conditions being in place. We thus caution against popular suggestions for firms to unleash their internal entrepreneurial potential by focusing solely on removing barriers to creativity in structure, systems, and culture (e.g., Bennett \& Marks, 2015). Such suggestions are biased towards encouraging innovative behaviors, which is not intrinsically a bad thing, but they ignore the importance of balancing the contradictory demands for established businesses to rely on proven templates, and those for emerging businesses to develop new templates.

Second, the corporate entrepreneurship literature has long recognized the cascading effect from transformational leaders to lower echelons through instilling new values and transforming organizational context, but it has downplayed the complexity and length of this process, involving different organizational actors at different stages (Dess et al., 2003). The varying importance of these organizational actors in the two stages implies that the key situational factors affecting outcomes will very likely differ too. By proposing specific situational factors in different stages, we have gone beyond prior research. We have provided evidence that the complex cascading process from TFL to CE needs to be unbundled further and that factors that contribute in the stage when the organizational context is being transformed may not matter much at the later stage when initiatives are identified and pursued. Our efforts at unbundling have also uncovered that little research has been undertaken on how actions at lower echelons aggregate into overall, firm-level behavior. Future research on TFL and firm behavior should specify not only the main organizational actors involved in each relevant stage but also clarify both the top-down cascading mechanisms from TFL to employee behavior and the bottom-up cascading processes from employee behavior to firm behavior. In particular, future research should deploy multilevel analysis, with data collected from top management, middle management, and frontline managers and employees, in order to understand fully how transformational leadership is related to corporate entrepreneurship.

Third, we have found that situational factors interact in complex ways and should not be viewed as being simply 'positive' or 'negative'. As our results demonstrate (Table V), in highly dynamic environments and structurally integrated organizations (low unit differentiation), increasing levels of TMT collectivism

(C) The Author(s), 2021. Published by Cambridge University Press on behalf of The International Association for Chinese Management Research 
can strengthen the pathway from TFL to CE through organizational ambidexterity. But in stable environments and structurally integrated organizations, low levels of TMT collectivism can enhance the pathway. Thus, the strength of moderators such as TMT collectivism depends upon the existence of other boundary conditions, thereby reflecting a combinatorial notion. In line with the tradition of viewing $\mathrm{CE}$ as an outcome of structure and processes (Dess et al., 2003), future studies of the TFL-CE linkages should consider not only complex interactions but also potential configurational effects.

Our study has a few limitations. The moderation effects in our analyses have small effect sizes and account for a relatively modest part of the variance in corporate entrepreneurship. Importantly, we tested for several mediating mechanisms proposed in the literature (e.g., TMT decentralization of responsibilities, risk propensity, and long-term compensation, Ling et al., 2008), but none of those appeared to be significant. It is conceivable that other mechanisms such as variation in organizational culture (Cameron \& Quinn, 2005) and a mix of situational factors might also contribute to explaining the long cascading process proposed. Analysis of TFL's effect on CE through organizational ambidexterity is complex subject matter; doing justice to the phenomenon might ultimately demand analysis of unique combinations of various external and internal situational factors. Future studies should not only test and compare multiple mediating mechanisms simultaneously but also include more qualitative inquiry as to how TFL can mobilize organizational resources to foster $\mathrm{CE}$.

Moreover, the theory we used puts forward causal relationships, but our empirical analysis is correlational in nature, and causality cannot be inferred without a longitudinal design or specific statistical interventions. For example, it is possible that corporate entrepreneurship strengthens organizational ambidexterity, which further stimulates CEOs to adopt a transformational leadership style, thereby suggesting reciprocal causality. Neither extant theory nor our post hoc analyses support such reversed causal relationship, but future research should examine this possibility through a longitudinal design. It remains challenging to track senior executives and middle managers across time, but such designs are sometimes feasible with the strong endorsement of trade associations, gifts to instigate a psychological sense of indebtedness, and other proven mechanisms (Bartholomew \& Smith, 2006). Another limitation is that our measurement of transformational leadership is based on a general scale and is not China-specific. Adding dimensions of TFL unique to the Chinese context, such as moral modeling (Li et al., 2015), might lead to a better fit with the Chinese context and yield more explanatory power.

\section{GONGLUSION}

We have shown that the mediating pathway from transformational leadership to corporate entrepreneurship through organizational ambidexterity is not significant

C The Author(s), 2021. Published by Cambridge University Press on behalf of The International Association for Chinese Management Research 
when boundary conditions are ignored. However, when environmental dynamism, TMT collectivism, and structural differentiation are included as moderators, CEO transformational leadership does affect corporate entrepreneurship via the creation and effective functioning of organizational ambidexterity. Our results suggest that transformational CEOs' endeavors to boost corporate entrepreneurship via the organizational ambidexterity will be effective only when a number of supporting factors are in place. One key finding for managerial practice on the basis of our data from China is that in a dynamic environment, higher TMT collectivism appears to go hand in hand with a stronger linkage between transformational leadership and the firm's ambidexterity. This is a first step towards higher corporate entrepreneurship in the firm. It means the CEO's selection of his or her immediate lieutenants matters much! In addition, and as a second step: within a more integrated organizational structure shared among all units, the linkages become stronger between transformational leadership and corporate entrepreneurship, via organizational ambidexterity. Finally, in a stable environment, it appears that transformational leaders need more individualistic TMT members for their actions to become associated with higher CE via organizational ambidexterity.

\section{NOTES}

[1] We propose that TMT collectivistic orientation and environmental dynamism moderate the first stage of the mediation process, but not the second stage. As initiatives from employees in the organization need to go through various layers of management, TMT collectivistic orientation will be less impactful on the relationship between organizational ambidexterity and corporate entrepreneurship than on the relationship between TFL and organizational ambidexterity. In addition, environmental dynamism may not affect at all the influence of organizational ambidexterity on corporate entrepreneurship, since designing and implementing organizational responses to environmental changes is the responsibility of the TMT, whereas middle managers and employees are much less sensitive to such environmental changes than TMTs. Importantly, our post hoc analyses did not lend support to the second stage moderation effect.

[2] For similar propositions of moderated mediation models based on separate mediation and moderation effects, see Cole et al., (2008).

[3] We received a total of 1,181 responses from TMT members. Besides the responses from 145 CEOs and 506 TMT members, which are included in the final regression analyses, we also obtained responses from another 530 TMT members, whose data were used to validate the measurement of the predictors. These TMT members represent firms where either the CEO or middle management did not ultimately complete the surveys.

[4] As some items of corporate entrepreneurship may not be applicable in specific contexts, researchers (e.g., Heavey, Simsek, Roche, \& Kelly, 2009; Ling et al., 2008) tend to delete items with low loadings in the CFA. For example, Ling et al. removed one item ('Has divested several unprofitable business units') because the small-to-medium-sized firms (SMEs) they sampled did not appear to engage in divesture activities. Heavey et al. (2009) deleted four items ('acquiring companies in different industries'; 'financing start-up business activities outside the organization'; 'creating new and semi-autonomous units'; and 'divesting several unprofitable business units') out of their 17-item scale of corporate entrepreneurship. Although the removed items in our study appear to be squarely in the construct domains of corporate entrepreneurship, they are not valid in our empirical context. The firms in our sample, on average, employ 2,023 individuals and have annual sales between RMB 10 million and 30 million. Thus, they represent the small and medium-sized enterprises (SMEs) according to the categorization standard applied by National Bureau of Statistics of China (http://www.stats.gov.cn/statsinfo/auto2073/201310/

(C) The Author(s), 2021. Published by Cambridge University Press on behalf of The International Association for Chinese Management Research 
t20131031_450691.html, in Chinese, accessed on April 20, 2017). In our post hoc interviews with 10 CEOs through ACFIC and 10 EMBA students at the Institute of Psychology, they noted that most of the SMEs in China have not been able to introduce 'breakthrough innovations' or be 'the first in the industry to introduce new business concepts and practices'. Neither divesture nor acquiring patents has become common practice among the private SMEs in China.

[5] Both TLF and RMSEA show indices that suggest an acceptable, but relatively mediocre fit, as both of them, have a penalty function to compensate parsimony (Brown, 2006: 85) and 'TLI and RMSEA tend to falsely reject models when $\mathcal{N}$ is small' (Brown, 2006: 86). As the CFI and the factor loadings are within the range of acceptable model fit, we suggest that our CEO measure fits the data well.

[6] In our post hoc interviews with 10 CEOs through ACFIC and 10 EMBA students at the Institute of Psychology, they noted that many SMEs in China tend to structure the R\&D function as a unit under the manufacturing department, which may have led to some confusion about the item stating 'innovation and production activities are structurally separated within our organization'.

[7] We should mention that a recent methodological contribution suggests the size of variance inflation factors not to be a good proxy for problems of multicollinearity in complex managerial and business settings, see Lindner, Puck, and Verbeke (2020).

[8] A detailed discussion of the Process macro can be found at the following website: http://www. afhayes.com/introduction-to-mediation-moderation-and-conditional-process-analysis.html (accessed February 7, 2017).

\section{APPENDIX I}

\section{GFA Results for Corporate Entrepreneurship}

\begin{tabular}{|c|c|c|}
\hline Corporate entrepreneurship: The extent to which the firm & $\begin{array}{l}\text { Construct } \\
\text { reliability }\end{array}$ & $\begin{array}{l}\text { Standardized } \\
\text { loadings }\end{array}$ \\
\hline \multicolumn{3}{|l|}{ Innovation } \\
\hline $\begin{array}{l}\text { Has spent heavily (well above the industry average) on product } \\
\text { development }\end{array}$ & & 0.75 \\
\hline Has introduced a large number of new products to the market & & 0.75 \\
\hline \multicolumn{3}{|l|}{$\begin{array}{l}\text { Has acquired significantly more patents than its major competi- } \\
\text { tors (Removed) }\end{array}$} \\
\hline \multicolumn{3}{|l|}{$\begin{array}{l}\text { Has pioneered the development of breakthrough innovations in } \\
\text { its industry (Removed) }\end{array}$} \\
\hline Has spent on new product development initiatives & & 0.69 \\
\hline \multicolumn{3}{|l|}{ Venturing } \\
\hline \multicolumn{3}{|l|}{ Has entered new markets (Removed) } \\
\hline Has established or sponsored new ventures & & 0.76 \\
\hline Has found new niches in current markets & & 0.74 \\
\hline Has financed start-up business activities & & 0.78 \\
\hline Has created new semi and autonomous units & & 0.80 \\
\hline \multicolumn{3}{|l|}{ Strategic renezual } \\
\hline $\begin{array}{l}\text { Has changed its competitive approach (strategy) for each business } \\
\text { unit }\end{array}$ & & 0.72 \\
\hline $\begin{array}{l}\text { Has recognized operations, units, and divisions to ensure } \\
\text { increased coordination and communication among business } \\
\text { units }\end{array}$ & & 0.82 \\
\hline Has redefined the industries in which it competes & & 0.76 \\
\hline Has introduced innovative human resource programs & & 0.72 \\
\hline $\begin{array}{l}\text { Has been first in the industry to introduce new business concepts } \\
\text { and practices (Removed) }\end{array}$ & & \\
\hline
\end{tabular}

(C) The Author(s), 2021. Published by Cambridge University Press on behalf of The International Association for Chinese Management Research 
[8] Continued

Corporate entrepreneurship: The extent to which the firm

The firm has divested several unprofitable business units.

(Removed)

Corporate entrepreneurship (second-order)

innovation

\section{APPENDIX II}

\section{GFA Results for Environmental Dynamism, Structural Differentiation, TMT Collectivism, and Transformational Leadership}

\begin{tabular}{|c|c|c|}
\hline & $\begin{array}{l}\text { Construct } \\
\text { reliability }\end{array}$ & $\begin{array}{l}\text { Standardized } \\
\text { loadings }\end{array}$ \\
\hline Environmental dynamism & 0.79 & 0.77 \\
\hline $\begin{array}{l}\text { Very dynamic, changing rapidly in technical, economic, and } \\
\text { cultural dimensions }\end{array}$ & & 0.63 \\
\hline Very risky, one false step can mean the firm's undoing & & 0.75 \\
\hline $\begin{array}{l}\text { Very rapidly expanding through the expansion of old markets } \\
\text { and the emergence of new ones }\end{array}$ & & 0.66 \\
\hline \multicolumn{3}{|l|}{ Very stressful, exacting, hostile, hard to keep afloat } \\
\hline Structural differentiation & 0.66 & \\
\hline $\begin{array}{l}\text { Innovation and production activities are structurally separated } \\
\text { within our organization (Removed) }\end{array}$ & & 0.45 \\
\hline $\begin{array}{l}\text { Our business units are specialized in specific functions and/or } \\
\text { markets }\end{array}$ & & 0.65 \\
\hline We serve our customers' needs from separate departments & & \\
\hline $\begin{array}{l}\text { The line and staff departments are clearly separated within our } \\
\text { organization }\end{array}$ & & 0.65 \\
\hline \multicolumn{3}{|l|}{$\begin{array}{l}\text { Our organization has separate units to enhance innovation and } \\
\text { flexibility (Removed) }\end{array}$} \\
\hline $\begin{array}{l}\text { We have units that are either focused on the short term or the } \\
\text { long term }\end{array}$ & & 0.51 \\
\hline TMT collectivism & 0.77 & \\
\hline $\begin{array}{l}\text { All the members of a successful acquisition team agreed to } \\
\text { equally share a large bonus, even though some members only } \\
\text { played a marginal role }\end{array}$ & & 0.72 \\
\hline $\begin{array}{l}\text { Because one member of the team did not do an equal share } \\
\text { of the work, the team requested that this member receive } \\
\text { a smaller share of the annual bonus (reverse-scored) } \\
\text { (Removed) }\end{array}$ & & \\
\hline $\begin{array}{l}\text { A team decided to share its bonus equally, although not all } \\
\text { members did the same amount of work on the project }\end{array}$ & & 0.77 \\
\hline
\end{tabular}

(C) The Author(s), 2021. Published by Cambridge University Press on behalf of The International Association for Chinese Management Research 
[8] Continued

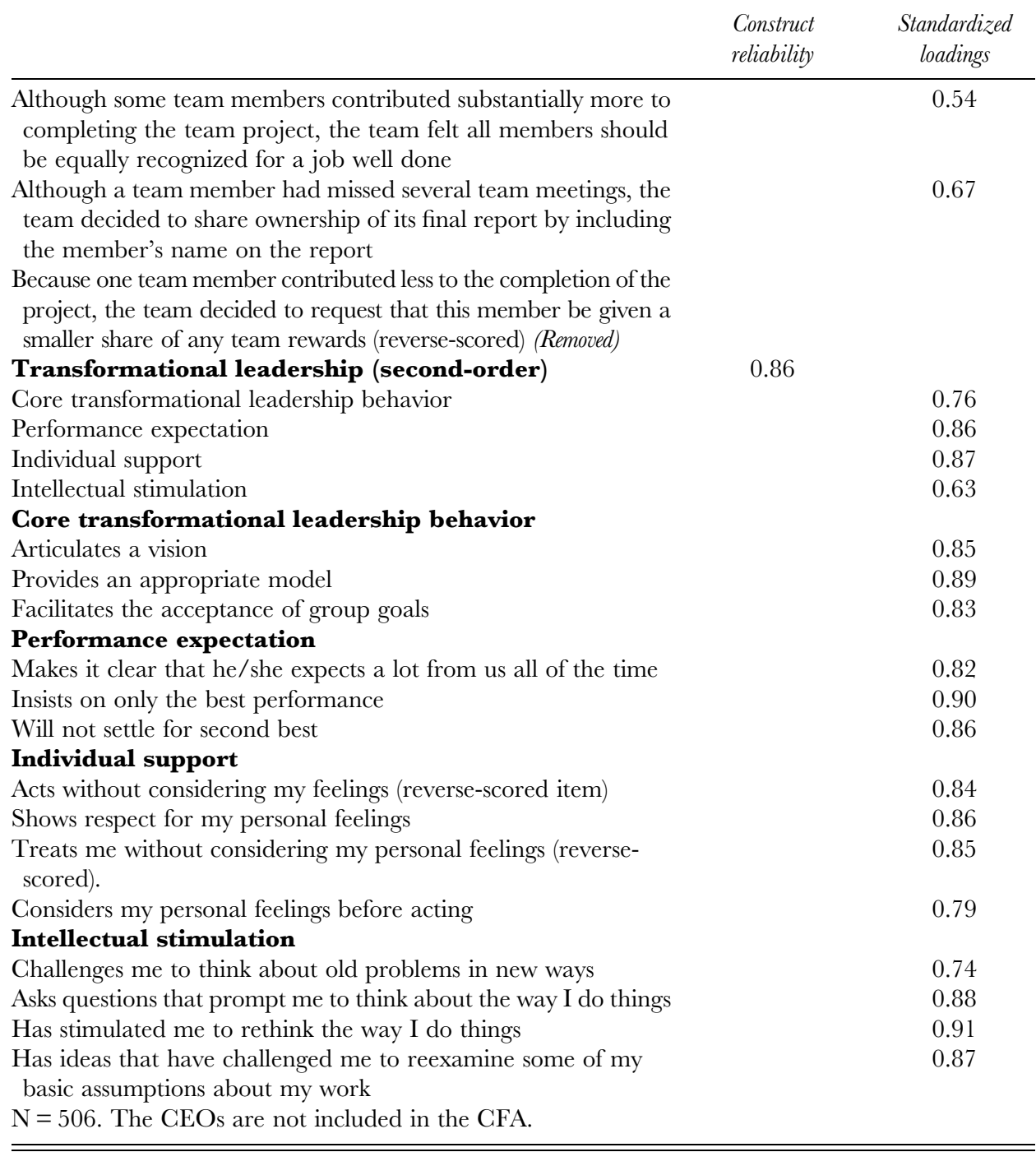

\section{REFERENGES}

Agle, B. R., Nagarajan, N. J., Sonnenfeld, J. A., \& Srinivasan, D. 2006. Does CEO charisma matter? An empirical analysis of the relationships among organizational performance, environmental uncertainty, and top management team perceptions of CEO charisma. Academy of Management Journal, 49(1): 161-174.

Amabile, T. M. 1998. How to kill creativity. Harvard Business Reviewe, 76(9): 77-87.

Bartholomew, S., \& Smith, A. D. 2006. Improving survey response rates from chief executive officers in small firms: The importance of social networks. Entrepreneurship Theory and Practice, 30(1): 83-96.

Bass, B. M. 1999. Two decades of research and development in transformational leadership. European Journal of Work and Organizational Psychology, 8(1): 9-32.

Bennett, N., \& Parks, J. M. 2015. Struggling to innovate? Examine your structure, systems, and culture. Business Horizons, 58(5): 563-569.

(C) The Author(s), 2021. Published by Cambridge University Press on behalf of The International Association for Chinese Management Research 
Berson, Y., Oreg, S., \& Dvir, T. 2007. CEO values, organizational culture and firm outcomes. Journal of Organizational Behavior, 29(5): 615-633.

Bliese, P. D. 2000. Within-group agreement, non-independence, and reliability: Implications for data aggregation and analysis. In K. Klein, \& S. Kozlowski (Eds.), Multilevel theory research, and methods in organizations: Foundations, extension, and neze directions: 349 381. San Francisco, CA: Jossey-Bass.

Bradley, S. W., Shepherd, D. A., \& Wiklund, J. 2011. The importance of slack for new organizations facing 'tough' environments. Journal of Management Studies, 48(5): 1071-1097.

Brown, T. A. 2006. Confirmatory factor analysis for applied research. New York: Guilford Press.

Burgers, J. H., Jansen, J. J. P., Van den Bosch, F. A. J., \& Volberda, H. W. 2009. Structural differentiation and corporate venturing: The moderating role of formal and informal integration mechanisms. Journal of Business Venturing, 24(3): 206-220.

Cameron, K. S., \& Quinn, R. E. 2005. Diagnosing and changing organizational culture: Based on the competing values framezork. San Francisco, CA: John Wiley \& Sons.

Cohen, J. 1988. Statistical pozer analysis for the behavioral sciences (2nd ed.). Hillsdale, NJ: Erlbaum.

Cole, M. S., Walter, F., \& Bruch, H. 2008. Affective mechanisms linking dysfunctional behavior to performance in work teams: A moderated mediation study.Journal of Applied Psychology, 93(5): 945-958.

Dess, G. G., Ireland, R. D., Zahra, S. A., Floyd, S. W., Janney, J. J., \& Lane, P. J. 2003. Emerging issues in corporate entrepreneurship. Journal of Management, 29(3): 351-378.

Dyer J., \& Gregersen, H. 2013. The secret to unleashing genius. Forbes. [Cited 24 January 2016]. Available from URL: http://www.forbes.com/sites/innovatorsdna/2013/08/14/the-secret-tounleashing-genius/

Fauchart, E., \& Gruber, M. 2011. Darwinians, communitarians, and missionaries: The role of founder identity in entrepreneurship. Academy of Management Journal, 54(5): 935-957.

Flynn, F. J., \& Chatman, J. A. 2001. Strong cultures and innovation: Oxymoron or opportunity. In C. L. Cooper, S. Cartwright, \& P. C. Earley (Eds.), International handbook of organizational culture and climate: 263-287. Sussex, NJ: John Wiley \& Sons

Galvin, B. M., Balkundi, P., \& Waldman, D. A. 2010. Spreading the word: The role of surrogates in charismatic leadership processes. Academy of Management Revieze, 35(3): 477-494.

Garvin, D. A., \& Levesque, L. C. 2006. Meeting the challenge of corporate entrepreneurship. Harvard Business Revieze, 84(10): 102-112.

Gibson, C. B., \& Birkinshaw, J. 2004. The antecedents, consequences, and mediating role of organizational ambidexterity. Academy of Management Joumal, 47(2): 209-226.

Goncalo, J. A., \& Staw, B. M. 2006. Individualism-collectivism and group creativity. Organizational Behavior and Human Decision Processes, 100(1): 96-109.

Goodale, J. C., Kuratko, D. F., Hornsby, J. S., \& Covin, J. G. 2011. Operations management and corporate entrepreneurship: The moderating effect of operations control on the antecedents of corporate entrepreneurial activity in relation to innovation performance. Journal of Operations Management, 29(1-2): 116-127.

Greve, H. 2018. Show me the data! Improving evidence presentation for publication. Management and Organization Revieze, 14(2): 423-432.

Gumusluoğlu, L., \& Ilsev, A. 2009. Transformational leadership, creativity, and organizational innovation. Journal of Business Research, 62(4): 461-473.

Hair, J. F., Black, W. C., Babin, B. J., \& Anderson, R. E. 2009. Multivariate data analysis. Upper Saddle River, New Jersey: Prentice Hall.

Hambrick, D. C., \& Mason, P. A. 1984. Upper echelons: The organization as a reflection of its top managers. Academy of Management Revieze, 9(2): 193-206.

Hayes, A. F. 2013. Introduction to mediation, moderation, and conditional process analysis: A regression-based approach. New York, NY: Guilford Press.

Heavey, C., Simsek, Z., Roche, F., \& Kelly, A. 2009. Decision comprehensiveness and corporate entrepreneurship: The moderating role of managerial uncertainty preferences and environmental dynamism. Journal of Management Studies, 46(8): 1289-1314.

Hornsby, J. S., Kuratko, D. F., \& Zahra, S. A 2002. Middle managers' perception of the internal environment for corporate entrepreneurship: assessing a measurement scale. Journal of Business Venturing, 17(3): 253-273.

Ireland, R. D., Covin, J. G., \& Kuratko, D. F. 2009. Conceptualizing corporate entrepreneurship strategy. Entrepreneurship Theory and Practice, 33(1): 19-46. 
Jansen, J. J. P., Tempelaar, M. P., Van den Bosch, F. A. J., \& Volberda, H. W. 2009. Structural differentiation and ambidexterity: The mediating role of integration mechanisms. Organization Science, 20(4): 797-811.

Jansen, J. J. P., Vera, D., \& Crossan, M. 2009. Strategic leadership for exploration and exploitation: The moderating role of environmental dynamism. Leadership Quarterly, 20(1): 5-18.

Jung, D. I., Chow, C., \& Wu, A. 2003. The role of transformational leadership in enhancing organizational innovation: Hypotheses and some preliminary findings. Leadership Quarterly, 14 (4): 525-544.

Kenny, D. A., \& La Voie, L. 1985. Separating individual and group effects.Journal of Personality and Social Psychology, 48(2): 339-348.

Kim, U., Triandis, H. G., Kagitcibasi, G., Choi, S.-C., \& Yoon, G. 1994. Individualism and collectivism: Theory, method, and applications. Thousand Oaks, CA: Sage Publications.

Kirkman, B. L., Chen, G., Farh, J. L., Chen, Z. X., \& Lowe, K. B. 2009. Individual power distance orientation and follower reactions to transformational leaders: A cross-level, cross-cultural examination. Academy of Management Joumal, 52(4): 744-764.

Kuratko, D. F., Hornsby, J. S., \& Covin, J. G. 2014. Diagnosing a firm's internal environment for corporate entrepreneurship. Business Horizons, 57(1): 37-47.

Lawrence, P. R., \& Lorsch, J. W. 1967. Differentiation and integration in complex organizations. Administrative Science Quarterly, 12(1): 1-47.

LeBreton, J. M., \& Senter, J. L. 2008. Answers to 20 questions about interrater reliability and interrater agreement. Organizational Research Methods, 11(4): 815-852.

Levine, S. 2018. Show us your data: Connect the dots, improve science. Management and Organization Review, 14(2): 433-437.

Li, C. P., Zhao, H., \& Begley, T. M. 2015. Transformational leadership dimensions and employee creativity in China: A cross-level analysis. Journal of Business Research, 68(6): 1149-1156.

Lindner, T., Puck, J., \& Verbeke, A. 2020. Misconceptions about multicollinearity in international business research: Identification, consequences, and remedies. Journal of International Business Studies, 51(3): 283-298.

Ling, Y., Simsek, Z., Lubatkin, M. H., \& Veiga, J. F. 2008. Transformational leadership's role in promoting corporate entrepreneurship: Examining the CEO-TMT interface. Academy of Management Journal, 51(3): 557-576.

Miller, D., \& Friesen, P. H. 1983. Strategy-making and environment: The third link. Strategic Management Journal, 4(3): 221-235.

Nemeth, C. J., \& Staw, B. M. 1989. The tradeoffs of social control and innovation in small groups and organizations. In L. Berkowitz (Ed.), Advances in experimental social psychology, Vol. 22: 175-210. New York, NY: Academic Press.

Podsakoff, P. M., MacKenzie, S. B., Moorman, R. H., \& Fetter, R. 1990. Transformational leader behaviors and their effects on followers' trust in leader, satisfaction, and organizational citizenship behaviors. Leadership Quarterly, 1(2): 107-142.

Ren, C. R., \& Guo, G. 2011. Middle managers' strategic role in the corporate entrepreneurial process: Attention-based effects. Journal of Management, 37(6): 1586-1610.

Rosing, K., Frese, M., \& Bausch, A. 2011. Explaining the heterogeneity of the leadership-innovation relationship: Ambidextrous leadership. Leadership Quarterly, 22(5): 956-974.

Sarason, Y., Dean, T., \& Dillard, J. F. 2006. Entrepreneurship as the nexus of individual and opportunity: A structuration view. Journal of Business Venturing, 21(3): 286-305.

Sathe, V. 2003. Corporate entrepreneurship: Top managers and new business creation. Cambridge, UK: Cambridge University Press.

Schaubroeck, J., Lam, S. S. K., \& Cha, S. E. 2007. Embracing transformational leadership: Team values and the impact of leader behavior on team performance. Journal of Applied Psychology, 92(4): 1020-1030.

Simons, T., Pelled, L. H., \& Smith, K. A. 1999. Making use of difference: Diversity, debate, and decision comprehensiveness in top management teams. Academy of Management Journal, 42(6): 662-673.

Simsek, Z., Heavey, C., Veiga, J. F., \& Souder, D. 2009. A typology for aligning organizational ambidexterity's conceptualizations, antecedents, and outcomes. Journal of Management Studies, 46(5): 864-894.

Simsek, Z., Veiga, J. F., Lubatkin, M. H., \& Dino, R. N. 2005. Modeling the multilevel determinants of top management team behavioral integration. Academy of Management Journal, 48(1): 69-84.

(C) The Author(s), 2021. Published by Cambridge University Press on behalf of The International Association for Chinese Management Research 
Srivastava, A., \& Lee, H. 2005. Predicting order and timing of new product moves: The role of top management in corporate entrepreneurship. Journal of Business Venturing, 20(4): 459-481.

Vaccaro, I. G., Jansen, J. J. P., Van Den Bosch, F. A. J., \& Volberda, H. W. 2012. Management innovation and leadership: The moderating role of organizational size. Jourmal of Management Studies, 49(1): 28-51.

Välikangas, L. 2018. Introduction to 'show me the data! Improving evidence presentation for publication' and 'show us your data: Connect the dots, improve science'. Management and Organization Revieze, 14(2): 421-421.

Vera, D., \& Crossan, M. 2004. Strategic leadership and organizational learning. Academy of Management Revieze, 29(2): 222-240.

Waldman, D. A., Ramirez, G. G., House, \& R. J., Puranam, P. 2001. Does leadership matter? GEO leadership attributes and profitability under conditions of perceived environmental uncertainty. Academy of Management Journal, 44(1): 134-143.

Waldman, D. A., \& Yammarino, F.J. 1999. CEO charismatic leadership: Levels-of-management and levels-of-analysis effects. Academy of Management Revieze, 24(2): 266-285.

Wei, L. Q., \& Ling, Y. 2015. CEO characteristics and corporate entrepreneurship in transition economies: Evidence from China. Journal of Business Research, 68(6): 1157-1165.

Zahra, S. A. 1996. Governance, ownership, and corporate entrepreneurship: The moderating impact of industry technological opportunities. Academy of Management Journal, 39(6): 1713 1735 .

Yaotian Pan (panyt@psych.ac.cn/yaotianpan@sohu.com) is an Associate Professor at the Institute of Psychology, the Chinese Academy of Sciences. $\mathrm{He}$ received his $\mathrm{PhD}$ in Organizational Behaviour and Strategic Management from the Haskayne School of Business at the University of Calgary, Canada. His research interests include cultural and work values, top management team decision-making, and innovation.

Alain Verbeke (averbeke@ucalgary.ca) is Editor-in-Chief of the Fournal of International Business Studies. He holds the McCaig Chair in Management at the Haskayne School of Business, University of Calgary (Canada). He is the Inaugural Alan Rugman Memorial Fellow at the Henley Business School, University of Reading (UK) and an Adjunct Professor at the Solvay Business School, Vrije Universiteit Brussel (Belgium). Dr. Verbeke is a Fellow of the Academy of International Business and European International Business Academy.

Wenlong Yuan (wenlong.yuan@umanitoba.ca) is the Stu Clark Chair in entrepreneurship and innovation at the Asper School of Business, University of Manitoba, Canada. His main research interests cross entrepreneurship, strategy, and international business. His work focuses on entrepreneurship in large firms, the impact of top management teams' characteristics on middle-level entrepreneurial activities, and behaviors of academic entrepreneurs.

Manuscript received: March 4, 2019

Final version accepted: July 13, 2020 (number of revisions - 4) 